\title{
Emergency awake fibreoptic intubation with confirmed COVID-19
}

\author{
Kira J. Tone, MD, FRCPC (1) - Gian-Marco C. Busato, MD, MSc, FRCSC • \\ Sena Aflaki, MD, FRCPC · Terence Ip, MD, FRCPC - Sheldon Lyn, MD, FRCPC
}

Received: 14 June 2021 / Revised: 14 July 2021 / Accepted: 21 July 2021 / Published online: 5 August 2021

(C) Canadian Anesthesiologists' Society 2021

Keywords Emergency · fibreoptic intubation · COVID-19 $\cdot$ case report

To the Editor,

The COVID-19 pandemic has changed the way physicians manage aerosol-generating medical procedures (AGMPs). Awake fibreoptic intubations (AFOIs) are extremely aerosol-generating, ${ }^{1}$ and as such carry a high risk of transmitting respiratory infections. ${ }^{2}$ We describe a case of an AFOI in a patient with impending airway obstruction who had confirmed COVID-19. Written consent was obtained from the patient to publish this case.

In February 2021, during the second wave of the COVID-19 pandemic in Ontario, Canada, a 32-yr-old male presented at $9 \mathrm{pm}$ to the emergency department of a large regional community hospital after having had a wisdom tooth extraction seven days prior. A computed tomography scan showed a large, left-sided, deep neck space abscess spanning the parapharyngeal space extending to the skull base, down to the level of the thyroid cartilage with airway compression down to $0.6 \mathrm{~cm}$ (Figure). $\mathrm{He}$ had a Mallampati class 4 airway with minimal mouth opening and neck extension. On nasal endoscopy, there was edema, deviation of the larynx, and moderate limitation of vocal cord abduction from mass effect. The patient was taken to the operating room $(\mathrm{OR})$ for incision and drainage with AFOI and possible tracheostomy.

K. J. Tone, MD, FRCPC ( $₫)$ - G.-M. C. Busato, MD, MSc, FRCSC - S. Aflaki, MD, FRCPC - T. Ip, MD, FRCPC .

S. Lyn, MD, FRCPC

Department of Anesthesiology, Southlake Regional Health

Centre, Newmarket, ON, Canada

e-mail: ktone@ southlakeregional.org
Upon arrival to the OR, the team was notified that the patient was newly positive for COVID-19. All members of the team were fully vaccinated and wore at least the minimum personal protective equipment (PPE) required. This included N95 masks, face shields, waterproof gowns, and gloves. The OR was protected and positive pressure air flow was exchanging 20 times per hour. The challenges anticipated included a difficult airway in a patient who was in respiratory distress, active COVID-19 infection, and an after-hours setting with limited support.

Airway topicalization was achieved with $2 \%$ lidocaine using a multi-holed closed-end epidural catheter slowly advancing to the back of the oropharynx. This was critical in this patient with limited mouth opening with a goal of minimal coughing. During topicalization, the surgeon marked and injected local anesthetic to the anterior neck and remained scrubbed for possible emergency tracheostomy. Once sufficiently topicalized, judicious sedation was administered to maintain spontaneous breathing. On bronchoscopy, much of the oropharynx was unidentifiable because of swelling and secretions. The vocal cords were viewed (although they were deviated to the right) and an endotracheal tube was passed through with minimal coughing. The surgery was uneventful and the patient was transported to the intensive care unit under sedation and with intubation.

Current recommendations for the intubation of patients with COVID-19 include deep sedation and full paralysis to minimize coughing and the aerosolization of the virus. ${ }^{3}$ Unlike during other COVID-19 intubations, the endotracheal tube could not be clamped or have the filter attached because of the fibreoptic scope's presence in the tube's lumen. There have been recommendations to have plastic coverings, ${ }^{4}$ have intubation boxes, ${ }^{1}$ be lying flat, have negative pressure rooms, and only allow essential 


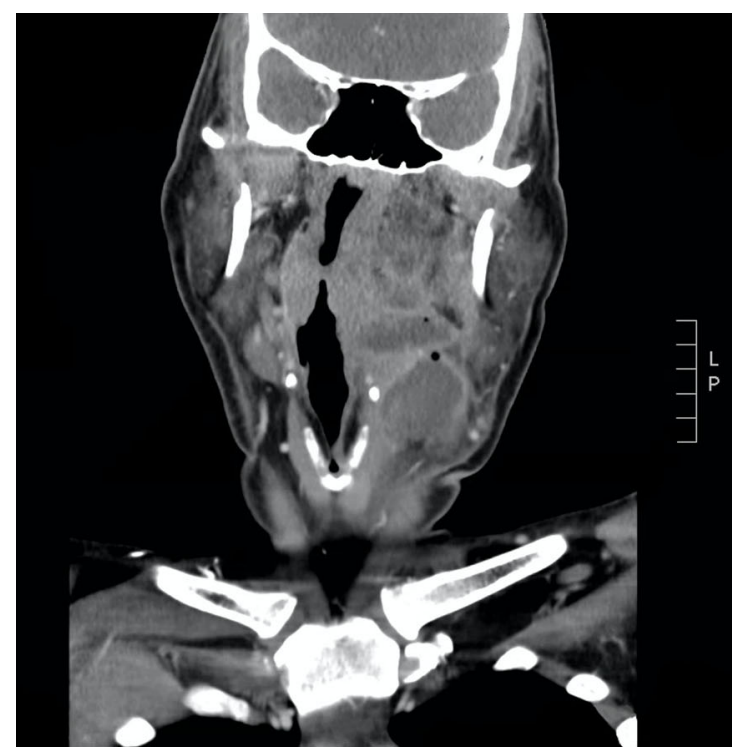

Figure Computed tomography scan of the head and neck with contrast-coronal (left) and axial (right)—of the patient preoperatively. The coronal projection shows the abscess spanning the left parapharyngeal space from the skull base down to the level of

personnel in the room. ${ }^{5}$ Many of these are not possible during AFOIs. Topicalization can usually be done in a variety of ways; however, nebulization and atomization are avoided when there is potential for aerosolized SARSCoV-2 virus; ${ }^{5}$ thus, we topicalized slowly with the multiholed epidural catheter and had very little coughing. The recovery room nurses were trained in doffing and played a crucial role in ensuring the safe removal of PPE. ${ }^{5}$ No staff became infected after this high-risk exposure.

There are several important lessons to be gained from this case. First, it is critical to maintain a high level of caution for all contacts during this global pandemic. Second, vigilant PPE practices with proper doffing and vaccination are likely effective at avoiding transmission. Finally, as with all difficult team challenges, concise and clear communication is critical for team success.

\section{Disclosures None.}

\section{Funding statement None.}

Editorial responsibility This submission was handled by Dr. Philip M. Jones, Deputy Editor-in-Chief, Canadian Journal of Anesthesial Journal canadien d'anesthésie.

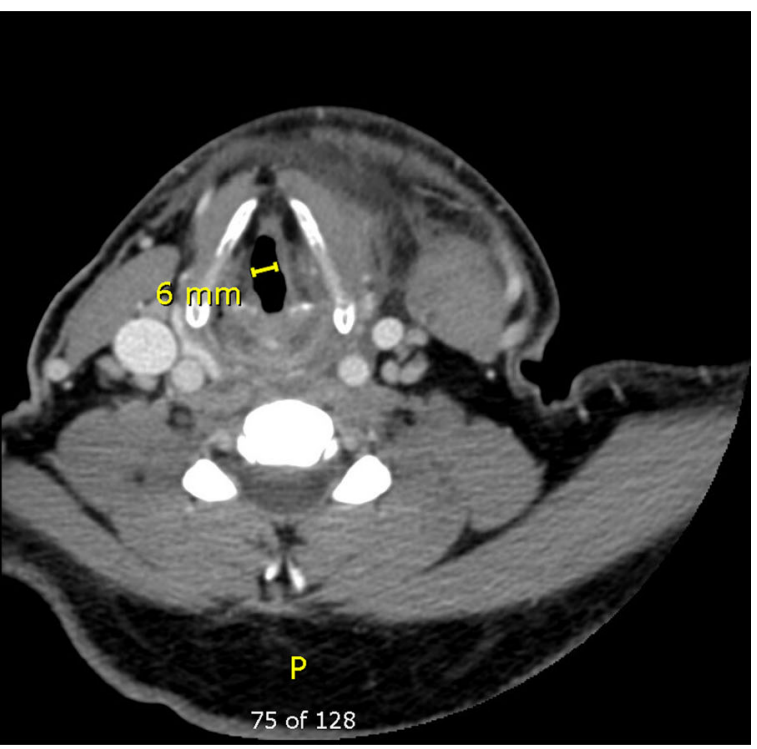

the larynx. Air is visible in the collections. The axial image shows narrowing of the oropharyngeal airway.

\section{References}

1. Emery AR, Saniukovich O, Lang AL, Tannyhill RJ III, Wang J. A novel approach to fiberoptic intubation in patients with coronavirus disease 2019. J Oral Maxillofac Surg 2020; 78: P2182.E1-6.

2. van Doremalen N, Bushmaker T, Morris DH, et al. Aerosol and surface stability of SARS-CoV-2 as compared with SARS-CoV-1. N Engl J Med 2020; 382: 1564-7.

3. Smith JD, Chen MM, Balakrishnan $K$, et al. The difficult airway and aerosol-generating procedures in COVID-19: timeless principles for uncertain times. Otolaryngol Head Neck Surg 2020; 163: 934-7.

4. Ghaly R, Perciuleac Z, Pleasca A, et al. Innovative overhead transparent plastic barrier with powered suction technique intended to limit coronavirus disease 2019 aerosols spread during fiber-optic intubation and throughout the surgery. Surg Neurol Int 2020; DOI: https://doi.org/10.25259/SNI_801_2020

5. Chao TN, Atkins JH, Qasim Z, Kearney JJ, Mirza N, Rassekh CH. Airway management of angioedema patients during the COVID19 pandemic. World J Otorhinolaryngol Head Neck Surg 2020; 6(Suppl 1): S36-9.

Publisher's Note Springer Nature remains neutral with regard to jurisdictional claims in published maps and institutional affiliations. 